\title{
Endocrine disruptors and congenital anomalies
}

\author{
Desreguladores endócrinos e anomalias congênitas
}

Mônica Rittler 1

Eduardo E. Castilla 2

\footnotetext{
1 Estudio Colaborativo Latinoamericano de Malformaciones Congénitas, Hospital Materno Infantil Ramon Sardá. Tucumán 3130, Olivos, Buenos Aires, 1636, Argentina.

2 Departamento de Genética, Instituto Oswaldo Cruz, Fundação Oswaldo Cruz. C. P. 926, Rio de Janeiro, $R J$ 20001-970, Brasil. castilla@centroin.com.br
}

\begin{abstract}
The specialized literature was reviewed concerning the suspected increasing secular trends in the frequency of female births, male genital congenital anomalies, abnormal sperm counts, and testicular cancer. Although no risk factors could be identified yet, the observed sex ratio decline during the last decades has been considered to be an effect of certain pollutants on normal hormone activity, and human reproductive development. Reported increasing trends in the frequencies of hypospadias and cryptorchidism are very difficult to be interpreted due to the large variability in the registered frequency of these malformations due to operational as well as biological reasons.
\end{abstract}

Key words Sex Ratio; Hypospadia; Cryptorchidism; Testicular Neoplasms; Endocrine Disruptors

Resumo Foi realizada revisão da literatura especializada, que diz respeito à suspeita de tendências seculares em aumento para os nascimentos femininos, as anomalias congênitas de genitais masculinos, contagens anormais de esperma e câncer testicular. Apesar de não terem ainda se identificado os fatores de risco envolvidos, o declínio da proporção de nascimentos masculinos nas últimas décadas tem sido considerado como um efeito de certos contaminantes sobre a atividade hormonal normal e o desenvolvimento reprodutivo. As tendências comunicadas para as freqüências crescentes observadas de hipospádias e criptorquidia são de difícil interpretação, sobretudo, em função da grande variabilidade na distribuição registrada destas malformações devido a motivos operacionais e biológicos.

Palavras-chave Razão de Masculinidade; Hipospadia; Criptorquidismo; Neoplasias Testiculares; Desreguladores Endócrinos 


\section{Introduction}

During the last decade, numerous studies have been published, reporting an increase in male reproductive organ anomalies, as well as in testicular cancer, and a decline in the relative number of male births, and in semen quality. At the same time, a growing number of therapeutical as well as environmental chemicals with recognized estrogenic, anti-androgenic or other hormonal activity have been focused on, as being potentially responsible for the mentioned anomalies. Many studies have been carried out, on experimental animals, as well as through observation of exposed human cohorts, in an attempt to gather evidence on the suspected developmental toxicity of these substances, in general referred to as endocrine disruptors.

\section{Observed anomalies and trends}

\section{Sex ratio}

Sex ratio is measured as the ratio of male to female births, and its normal value, with slight deviations, is considered to be of 1.06 , that is 106 males for every 100 females born (Davis et al., 1998).

Numerous factors have been associated with the gender of the newborn, as for instance, maternal age (Juntunen et al., 1997); gonadotrophin levels (James, 1980); interpregnancy intervals and seasonal effects (James, 1996); maternal diabetes (Rjasanowski et al., 1998); family size and birth order (Biggar et al., 1999); length of follicular phase and moment of conception (Jongbloet et al., 1996). Other factors have been associated with a reduction of male offspring, as older age of the fathers, in vitro fertilization, non Hodgkin lymphoma, hepatitis and use of fertility drugs, such as clomiphene (James, 1995).

Recent reports from several industrial countries (Denmark, the Netherlands, Canada and the United States) indicated a significant decline in the proportion of newborn males during the past three decades (Allan et al., 1997; Moller, 1996; van der Pal-de Bruin et al., 1997). In Denmark, the male proportion declined from 0.515 in 1950 to 0.513 in 1994 . In Netherlands, it declined from 0.516 in 1950 to 0.513 in 1994. Similar trends were observed in Canada and the United States. In Canada, the decline represented a cumulative loss of 2.2 male births per 1,000 live births, which would mean a whole reduction of 8,600 male births, for the 20 -year period between 1970 and 1990. In the United States the cumulative decrease was of 1.0 male births per 1,000 live births for the same period, which would mean a whole decrease of 38,000 male births. Another analysis of live births in the United States, between 1969 and 1995, showed a significant decline in male births among whites, but an increase among blacks (Marcus et al., 1998). Using data from 29 countries between 1950 and 1990, Parazzini et al. (1998) observed a sex ratio decline in 16 , an increase in 6 , while 7 remained stable. In some Latin American countries, the male proportion has also declined since the 1970 s, from 0.513 to 0.512 (Feitosa \& Krieger, 1992).

Although no risk factors could be identified in the mentioned studies, the observed sex ratio decline during the last twenty or thirty years has been considered by some authors as part of an apparently disruptive effect of certain substances on normal hormone activity, and thus indirectly, on human reproduction and development.

Some studies have considered the hypothesis that certain substances with teratogenic or even mutagenic effects could affect the normal sex determination of the embryo, which could then lead to an apparent female predominance, as, for instance, through somatic mutations of the SRY, the sex determining gene on the Y chromosome, or through events that could damage or impair Y chromosome-bearing sperm cells (Gustafson \& Donahoe, 1995). Similarly, insufficient androgens could produce a feminized male appearing to be a normal female. Other studies (James, 1986; Sas \& Szollosi, 1980) have considered hormonal imbalances, as altered levels of corticotrophin, gonadotrophin, testosterone and estrogen, in fathers as well as in mothers, to be related with the sex of the offspring.

Occupational and environmental exposures influencing sex at birth have also been identified by several studies. Workers exposed to the nematocide dibromochloropropane were found to have diminished sperm counts, elevated gonadotropin levels, and a reduced sex ratio in their offspring (Goldsmith et al., 1984); workers in the aluminum industry (Milham, 1993), and others exposed to organochlorine, as well as other pesticides, and waste anesthetic gases (Wyatt \& Wilson, 1973) had significantly more female than male offspring. Finally, the accidental release of dioxin, a toxicant with a recognized anti-estrogenic activity, and the following sex ratio decline in Seveso (1976, apud Mocarelli et al., 1996), lent further support to the hypothesis that environmental toxicants 
with endocrine activity, and thus creating hormonal imbalance, might be involved in lowering the sex ratio.

While some authors considered changes in the sex ratio as a potential sentinel health indicator (Davis et al., 1998), James (1998) suggested that it is not a useful monitor of reproductive hazard, but is instead distracting attention from the huge and unexplained changes in other monitors of reproductive hazard, e.g., the widespread decline in dizygotic twinning rates and the recent decline in sperm counts.

On the other hand, the concept of sex ratio is generally applied to the moment of birth, and existing evidence as to overall predominance of male mortality, probably starting shortly after the moment of conception and lasting throughout the whole lifetime, should be taken into account. Accurate data on the sex ratio at the moment of conception and at the earliest stages of human embryo development are lacking, and this precludes to draw solid conclusions as to the meaning of the very small, although significant, changes over time in sex ratio at birth.

\section{Hypospadias}

Hypospadias is one of the most common male genital anomalies (Zaontz \& Packer, 1997). It consists of an abnormal meatal opening on the ventral surface of the penis, the milder forms are distal, below the tip of the glans, the most severe ones are proximal, close to the perineum.

Until the eighth week of embryonic development, the fetus does not differentiate into male or female. After testicular differentiation of the primitive gonad, secretion of testicular androgens produces closure of the urogenital sinus. The genital tubercle enlarges to form the penis, and the labioscrotal folds fuse into the scrotum. The penile shaft grows, bringing with it the ventral extension of the urogenital sinus, which forms the urethral groove. The urethra closes, through fusion of the urogenital folds on either side of the urethral groove from proximal to distal. Hypospadias results through developmental arrest anywhere along the line of urethral fusion, but it occurs more frequently at the level of the coronal sulcus. It is mostly an isolated finding, but can sometimes be part of syndromes. The most common anomalies associated with hypospadias are undescended testes $(9.3 \%)$ and inguinal herniae $(9.1 \%)$, and in the more severe forms of hypospadias, these values could reach $31.6 \%$ and $17.0 \%$, respectively (Khuri et al., 1981). Conversely, and through a comparison of risk factors and patterns, Akre et al. (1999) found only a weak association between hypospadias and cryptorchidism. Bauer et al. (1981) surveyed family histories of patients with hypospadias, and found an $8 \%$ incidence in fathers, and a $12 \%$ recurrence rate in sibs.

Various endocrine pathways that may be part of the etiology of hypospadias have been investigated. In particular, attention has been focused on the hypothalamic-pituitary gonadal axis, the role of testosterone and its metabolites, and androgen receptors. Aarskog (1971), among others, suggested a link between progestin administration and hypospadias, while other studies suggested that the evidence for a risk of hypospadias associated with exposure to oral contraceptives and progestagens in early pregnancy was not strong (Raman-Wilms et al., 1995).

At present, the role of the endocrine system, though considered important in hypospadias development, remains unclear.

The observed incidence of hypospadias varies widely among the different reporting systems, (from 0.37-41 per 10,000) (Toppari \& Skakkebaek, 1998), a fact probably due to differences in diagnostic and reporting criteria. There are ethnic and geographical differences in the prevalence of hypospadias, with a higher rate in Caucasians than in African or Native Americans (Toppari \& Skakkebaek, 1998); Finland has a lower prevalence of hypospadias as well as of testicular cancer, than the neighboring Scandinavian countries.

During the last decade, increasing trends of hypospadias, among other male genital anomalies have been reported (Dolk, 1998; WHO, 1991), and the hypothesis has been raised that increasing levels of environmental agents with an estrogenic effect may be responsible for these trends, by interfering with the feedback mechanism of sex hormones at the pituitary gonadal axis during fetal development (Sharpe \& Skakkebaek, 1993). Nonetheless, the trends mentioned in these reports are controversial (Paulozzi, 1999).

Increases over time have mainly been reported in England and Wales, Hungary and the Scandinavian countries, while no trend was found in Finland, Spain, New Zealand, Australia and Czechoslovakia. Analyses of two American surveillance systems (the Metropolitan Atlanta Congenital Defects Program and the Birth Defects Monitoring Program) indicated that the rates of hypospadias have nearly doubled since 1970, reaching 39.7 per 10,000 in 1993. The authors (Paulozzi et al., 1997) suggested that this did not seem to be due to modified diagnostic criteria, as for example, the in- 
clusion of minor forms, since the ratio of minor to severe cases had decreased; in fact, the ratio of severe to mild forms increased threeto fivefold over the period, according to data from the Atlanta registry. Nonetheless, other systems showed no increase in the more severe forms, and data from the Finnish registry indicated a decline of the more serious forms of hypospadias, while overall rates increased.

As the development of male external genitalia is under hormonal control, the main hypotheses concerning such an increasing trend, have focused on endogenous hormone imbalance or on exposure to exogenous hormones. During gestation, the fetus is exposed to large amounts of pregnancy sex hormones, and the level of exposure varies primarily with gestational age, but also with other maternal and pregnancy characteristics. Akre et al. (1999) conducted a prospective, case-control study on the risk factors for both hypsopadias and cryptorchidism. They did not find any consistent support for an etiologic role of increased estrogen levels during pregnancy. The fact that during gestation the fetus is exposed to levels of female sex hormones hundreds of times higher than during postnatal life, plus the different time windows for urethral closure and testicular descent, make a coincidental exposure-effect quite unlikely. Furthermore, in their study, the infants with the highest risk for both anomalies were preterm, and small for gestational age, indicating relatively low exposure to estrogens. The authors concluded, instead, that uteroplacental malfunction may be a common denominator for both anomalies, although perhaps acting in different ways.

\section{Cryptorchidism}

Cryptorchidism is a condition in which one or both testicles do not descend into the scrotum. Testicular descent is not completed until the third trimester of gestation. An initial transabdominal phase of descent occurs at 10-15 weeks, and migration of the fetal testicle from groin to scrotum takes place at 26-35 weeks. (Hutson et al., 1994). Inguinal descent, the most common phase to be disrupted, is known to be testosterone dependent.

Data from the literature indicate that diagnostic criteria, examination methods and inclusion criteria are very variable, while different sources of data also add to the complexity; for example, information from registries seems to be not as reliable as data from clinical studies (Toppari \& Skakkebaek, 1998), and therefore, data obtained from different studies are difficult to compare. Furthermore, ethnic differences have been observed, as the incidence among African Americans was reported to be only one third of that among whites (Heinonen et al., 1977). Other studies have found no differences (Berkowitz et al., 1993), and at any rate, data concerning ethnicity have been pooled in most of the studies (Toppari \& Skakkebaek, 1998).

Estimates of cryptorchidism recorded at birth and up to adulthood vary widely (between 0.03 and 13.4\%) (Toppari \& Skakkebaek, 1998). Most of the studies do not refer to data at birth exclusively, but include patients of up to 1 year of age (Scorer, 1964), others are based on rates of orchidopexy, on diagnosis in school or army surveys, and obviously they all differ and are not comparable. Although several reports have indicated a substantial increase in the incidence at birth (Chilvers, 1992), others reported no changes over time (Berkowitz et al., 1993), and the data overall seem to show no consistent trends. Cryptorchidism in the United States presently occurs at about a $0.4 \%$ incidence in neonates (Paulozzi, 1999).

Data of the International Clearinghouse for Birth Defects Monitoring (ICBDMS), which analyzes rates of selected congenital anomalies at birth, indicated that in the United States and Canada, and according to three different registries, the rates increased during the 1970s and 1980s, and then seemed to stabilize or declined. Norway and the France-Paris system showed no consistent trend between 1974 and 1996. In England the rates dropped around 1990, Hungary also showed a peak and then declined, and only the South American rates increased since 1985 (Paulozzi, 1999).

Although only few systems report data on cryptorchidism, there seems to be no indication of a generalized increase over time. The marked observed differences between systems and the changes over time can be due to a number of factors, many of them artifacts, as for instance, the known association between cryptorchidism and testicular cancer which during recent years could have led to a more aggressive search for undescendend testes (Paulozzi, 1999).

\section{Testicular cancer}

Trends in testicular cancer show an increase of $60-70 \%$ during the last four decades in many European countries, North America and Australia, and mainly among Caucasians aged between 20 and 35 years. Although an association between testicular cancer and estrogen expo- 
sure has been observed in experimental models as well as in humans (mainly those exposed to diethylstilbestrol - DES), there are no studies that have analyzed the association between temporal trends and exposure to environmental chemicals (Barlow et al., 1999).

\section{Semen quality}

A meta-analysis of studies published between 1938 and 1990 suggested a decline in sperm concentration and semen volume over the last 50 years (Carlsen et al., 1992). Nonetheless, the authors admitted the existence of several shortcomings in the outline of such an analysis, as for instance, selection bias, variability in semen collection and analysis, especially with respect to the period of abstinence, and the appropriateness of the applied statistical methods. A re-analysis including part of the studies, led to the conclusion that the data were compatible with a decline, no change, or an improvement in semen quality. A second re-analysis that controlled for abstinence time, age, collection method, and group size, among other factors, concluded that a decline in sperm density was seen in the United States and Europe, but not in non-Western countries, between 1938 and 1988 (Swann et al., 1997).

Recent studies carried out in Belgium, France and Scotland reported reduction of semen quality over time, while others in United States, Finland and France reported no change. All these studies raised the hypothesis that there may be geographical variations without semen quality reduction over time in some areas, or reduction over time in some areas but not in others, rather than an overall decline over time worldwide.

It should be emphasized that the four conditions considered, namely, hypospadias, cryptorchidism, testicular cancer and semen quality are interrelated, and prevalence rates of congenital male reproductive anomalies and testicular cancer show a clear correlation in different countries. For example, Denmark has a high prevalence of hypospadias, cryptorchidism and testicular cancer, while in Finland all three rates are low. Furthermore, cryptorchidism is a risk factor not only for testicular cancer, but also for poor semen quality. Epidemiological data indicate that these condictions share risk factors, such as low birthweight and high maternal estrogen levels during pregnancy (Toppari \& Skakkebaek, 1998).

\section{Endocrine disruptors with estrogenic effect}

Perhaps the best-known and studied substance for its adverse human effects is DES, used during the 50 s and $60 \mathrm{~s}$, as a preventor of spontaneous abortion, among other effects. This drug was withdrawn from the market during the 70s, when a number of vaginal clear cell adenocarcinoma cases were reported in women exposed to DES in utero. Other effects, as congenital anomalies of male and female reproductive organs, have also been described among exposed offspring, for example, epididymal cysts, meatal stenosis, hypospadias, cryptorchidism, microphallus in males, and annular rings, ectropion, vaginal hypoplasia, uterine deformities and benign tumors in females. Several reports have shown that the semen quality of exposed men was significantly worse than in controls, while data on risk of testicular cancer are controversial (Toppari et al., 1996).

The list of environmental toxicants with weak estrogenic activity is growing, and it includes insecticides, industrial chemicals and pollutants, phyto- and mycoestrogens, and although human exposure to each one of them might be low, little is known about possible synergistic or additive effects, and it should be noted that many of these substances are currently used in large quantities. Although at present the risks as to adverse effects on human sexual differentiation associated with individual compounds are unknown, extensive data are available from animal experiments.

\section{Anti-androgenic effect}

Androgens are essential for male differentiation and function of normal male reproductive organs, and exposure of the male fetus to antiandrogens would result in a variable degree of feminization, depending on the agent, timing and dose. In several environmental toxicants, as the fungicide vinclozolin, such an anti-androgenic activity has been shown to exist, although only in experimental animals, producing reduced anogenital distance, hypospadias and cryptorchidism in male rats, while females were, as expected, normal. There are no data available on human intra-uterine exposure to vinclozolin. In an occupational study carried out in workers involved in the synthesis of this chemical (Zober et al., 1995), the investigators concluded that there was no evidence of any health effects with long term, but low level exposure, referring particularly to anti-andro- 
genic effects. However, in their results, they reported an apparent increase in testicular abnormalities, with a risk ratio of 4.5 , and significantly higher FSH levels than in controls. On the other hand, many of these men had predisposing conditions, as childhood cryptorchidism, which led the investigators to believe that the effect was not related to the vinclozolin exposure.

\section{Other endocrine disrupting effects}

An altered thyroid function can also affect sexual differentiation, and a number of environmental pollutants have been shown to exert such an antithyroid effect. Among these, 2,3,7,8tetrachlorodibenzo-p-dioxin, commonly referred to as dioxin, is considered as one of the most powerful toxicants, with an anti-thyroid, as well as anti-estrogenic effect. This substance and some of its congeners, are released during processing and incineration of chlorinated hydrocarbons, used as pesticides, solvents, plastics, or during the manufacture of paper, steel foundries, and motor vehicles. Studies on the exposure of experimental animals to these substances have shown multiple developmental anomalies in reproductive organs. In humans, suspicion of an association between dioxin and reproductive anomalies was raised after an accidental release of dioxin in Seveso, Italy, in 1976, and the observation of a reduced sex ratio among the nine families with the highest serum dioxin levels, during the following 10 years (Mocarelli et al., 1996). In a recent report, Mocarelli et al. (2000) concluded that serum levels lower than those already shown may have a similar effect if the father had been exposed, and even more so if the exposure was before or during puberty, indicating that this could be a very sensitive period for dioxin toxicity in men.
Although a direct causal relation between this substance and human sex differentiation has not been determined, the observation suggests that dioxin could modify hormonal balance.

Numerous environmental pollutants show interference with normal hormone activity, some of them with a clear adverse effect on reproductive organ development, although mainly in experimental animal models. However, the trends are controversial, and data concerning specific effects and affected pathways are still lacking.

\section{Congenital anomalies and endocrine disruptors in Latin America}

The Latin American Collaborative Study of Congenital Malformations (ECLAMC, <http:// www.biologia.ufrj.br/sociedades/eclamc/>) is a multicentric program involving a joint effort from several centers collecting data on birth defects in several Latin American countries (Argentina, Bolivia, Brazil, Colombia, Chile, Costa Rica, Dominican Republic, Equator, Paraguay, Peru, Uruguay and Venezuela). Evidence linking potential endocrine disruptors exposure, and birth defects has yet to be identified in this region (Castilla et al., 2000). Data analysis during the last 30 years (1967-1997) showed stable secular trends for secondary sex ratios, and for hypospadias. An increasing secular trend for undescended testis is evident, but its pathological meaning at birth, without deeper analysis, is questionable. To evaluate cryptorquidism secular trends, an investigation of the condition's prevalence in conscripts records from military health system databases is recommended, covering the yearly physical examination of young adult males for a period as far back as records permit.

\section{Acknowledgments}

This study was partially supported by the Agencia Nacional de Promoción Científica y Tecnológica, the Consejo Nacional de Investigaciones Científicas y Técnicas (CONICET) of Argentina, the Programa de Apoio a Pesquisa Estratégica em Saúde (PAPES) of Fundação Oswaldo Cruz, and the Conselho Nacional de Desenvolvimento Científico e Tecnológico (CNPq) of Brazil. 


\section{References}

AARSKOG, D., 1971. Intersex conditions masquerading as simple hypospadias. Birth Defects, 7:122130.

ALLAN, B. B.; BRANT, R.; SEIDEL, J. E. \& JARREL, J. F., 1997. Declining sex ratios in Canada. Canadian Medical Association Journal, 156:37-41.

AKRE, O.; LIPWORTH, L.; CNATTINGIUS, S.; SPARÉN, P. \& EKBOM, A, 1999. Risk factor patterns for cryptorchidism and hypospadias. Epidemiology, 10:364-369.

BARLOW, S.; KAVLOCK, R. J.; MOORE, J. A.; SCHANTZ, S. L.; SHEEHAN, D. M.; SHUEY, D. L. \& LARY, J. M., 1999. Teratology Society Public Affairs Committee position paper: Developmental toxicity of endocrine disruptors to humans. Teratology, 60:365-375.

BAUER, S. B.; RETIK, A. B. \& COLODNY, A. H., 1981. Genetic aspects of hypospadias. Urologic Clinics of North America, 8:559.

BERKOWITZ, G. S.; LAPINSKI, R. H.; DOLGIN, S. E.; GAZELLA, J. G.; BODIAN, C. A. \& HOLZMAN, I. R., 1993. Prevalence and natural history of cryptorchidism. Pediatrics, 92:44-49.

BIGGAR, R. J.; WOHLFAHRT, J.; WESTERGAARD, T. \& MELBYE, M., 1999. Sex ratios, family size, and birth order. American Journal of Epidemiology, 150:957-962.

CARLSEN, E.; GIWERCMAN, A.; KEIDING, N. \& SKAKKEBAEK, N. E., 1992. Evidence for decreasing quality of semen during past 50 years. $B M J$, 305:609-613.

CASTILLA, E. E.; CAMPANA, H. \& CAMELO, J. S., 2000. Economic activity and congenital anomalies: An ecologic study in Argentina. Environmental Health Perspectives, 108:193-197.

CHILVERS, C. E. D., 1992. Cryptorchidism: A prospective study of 7,500 consecutive male births, 19848. Archives of Disease in Childhood, 67:892-899.

DAVIS, D. L.; GOTTLIEB, M. B. \& STAMPNITZKY, J. R., 1998. Reduced ratio of male to female births in several industrial countries. A sentinel health indicator? JAMA, 279:1018-1023.

DOLK, H., 1998. Rise in prevalence of hypospadias. Lancet, 351:770.

FEITOSA, M. F. \& KRIEGER, H., 1992. Demography of the human sex ratio in some Latin American countries, 1967-1986. Human Biology, 64:523530.

GOLDSMITH, J.; POTASHNIK, G. \& ISRAELI, R., 1984. Reproductive outcomes in families of DBCP-exposed men. Archives of Environmental Health, 39:85-89.

GUSTAFSON, M. L. \& DONAHOE, P. K., 1995. Reproductive embryology and sexual differentiation. In: Reproductive Medicine and Surgery (E. E. Wallach \& H. A. Zacur, ed.), pp. 39-59, Saint Louis: Mosby-Year Book.

HEINONEN, O. P.; SLONE, D. \& SHAPIRO, S., 1977. Birth Defects and Drugs in Pregnancy. Littleton: Publishing Sciences Group.

HUTSON, J. M.; BAKER, M.; TERADA, M.; ZHOU, B. \& PAXTON, G., 1994. Hormonal control of testicular descent and the cause of cryptorchidism. Reproduction, Fertility, and Development, 6:151-156.
JAMES, W. H., 1980. Gonadotrophin and the human secondary sex ratio. $B M J$, 281:711-712.

JAMES, W. H., 1986. Hormonal control of sex ratio. Journal of Theoretical Biology, 118:427-441.

JAMES, W. H., 1995. What stabilizes the sex ratio? Annals of Human Genetics, 59:243-249.

JAMES, W. H., 1996. Interpregnancy intervals, high maternal age and seasonal effects on the human sex ratio. Human Reproduction, 11:7-9.

JAMES, W. H., 1998. Was the widespread decline in sex ratios at birth caused by reproductive hazards? Human Reproduction, 13:1083-1084.

JONGBLOET, P. H.; GROENEWOUD, J. M. M. \& ZIELHUIS, G. A., 1996. Further concepts on regulators of the sex ratio in human offspring. Human Reproduction, 11:2-9.

JUNTUNEN, K. S. T.; KVIST, A. P. \& KAUPPILA, A. J. I., 1997. A shift from a male to a female majority in newborns with the increasing age of grand multiparous women. Human Reproduction, 12:23212323.

KHURI, F. J.; HARDY, B. E. \& CHURCHILL, B. M., 1981. Urologic anomalies associated with hypospadias. Urologic Clinics of North America, 8:565.

MARCUS, M.; KIELY, J.; XU, F.; McGEEHEN, M. \& JACKSON, R. T., 1998. Changing sex ratio in the United States, 1969-1995. Fertility and Sterility, 70:270-273.

MILHAM, S., 1993. Unusual sex ratio of births to carbon setter fathers. American Journal of Industrial Medicine, 23:829-831.

MOLLER, H., 1996. Change in male-female ratio among newborn infants in Denmark. Lancet, 348:828-829.

MOCARELLI, P.; BRAMBILLA, P.; GERTHOUX, P. M.; PATTERSON, D. G. \& NEEDHAM, L. L., 1996 Change in sex ratio with exposure to dioxin. Lancet, 348:409.

MOCARELLI, P.; GERTHOUX, P. M.; FERRARI, E.; PATTERSON, D. G.; KIESZAK, S. M.; BRAMBILLA, P; VINCOLI, N.; SIGNORINI, S.; TRAMACERE, P.; CARRERI, V.; SAMPSON, E. J.; TURNER, W. E. \& NEEDHAM, L. L., 2000. Paternal concentrations of dioxin and sex ratio of offspring. Lancet, 355 : 1858-1863.

PARAZZINI, F.; LA VECCHIA, C.; LEVI, F. \& FRANCESCHI, S., 1998. Trends in male: Female ratio among newborn infants in 29 countries from five continents. Human Reproduction, 13:1394-1396.

PAULOZZI, L. J., 1999. International trends in rates of hypospadias and cryptorchidism. Environmental Health Perspectives, 107:297-302.

PAULOZZI, L. J.; ERICKSON, J. D. \& JACKSON, R. J., 1997. Hypospadias trends in two US surveillance systems. Pediatrics, 100:831-834.

RAMAN-WILMS, L.; TSENG, A. L. \& WIGHARDT, S. 1995. Fetal genital effects of first-trimester sex hormone exposure: A meta analysis. Obstetrics and Gynecology, 85:141-149.

RJASANOWSKI, I.; KLÖTING, I. \& KOVACS, P., 1998. Altered sex ratio in offspring of mothers with insulindependent diabetes mellitus. Lancet, 351:497-498.

SAS, M. \& SZOLLOSI, J., 1980. The sex ratio of children of fathers with spermatic disorders follow- 
ing hormone therapy. Orvosi Hetilap, 121:28072808.

SHARPE, R. M. \& SKAKKEBAEK, N. E., 1993. Are oestrogens involved in falling sperm counts and disorders of the male reproductive tract? Lancet, 29:1392-1395.

SCORER, C. G., 1964. The descent of the testis. Archives of Disease in Childhood, 39:605-609.

SWANN, S. H.; ELKIN, E. P. \& FENSTER, L., 1997. Have sperm counts declined? A reanalysis of global trend data. Environmental Health Perspectives, 105:1228-1232.

TOPPARI, J.; LARSEN, J. C. \& CHRISTIANSEN, P., 1996. Male reproductive health and environmental xenoestrogens. Environmental Health Perspectives, 104(Sup. 4):741-803.

TOPPARI, J. \& SKAKKEBAEK, N. E., 1998. Sexual differentiation and environmental endocrine disrupters. Bailliere's Clinical Endocrinology and Metabolism, 12:143-156.
VAN DER PAL-DE BRUIN, K. M.; VERLOOVE-VANHORICK, S. P. \& ROELEVELD, N., 1997. Change in male-female ratio among newborn babies in Netherlands. Lancet, 349:62.

WHO (World Health Organization), 1991. Congenital Malformations Worldwide: A Report from the International Clearinghouse for Birth Defects Monitoring Systems. Oxford: Elsevier.

WYATT, R. \& WILSON, A. M., 1973. Children of anesthetists. $B M J, 1: 675$.

ZAONTZ, M. R. \& PACKER, M. G., 1997. Abnormalities of the external genitalia. Pediatric Clinics of North America, 44:1267-1297.

ZOBER, A.; HOFFMANN, G. \& OTT, M. G., 1995. Study of morbidity of personnel with potential exposure to vinclozolin. Occupational and Environmental Medicine, 53:333-341.

Submitted on 7 July 2000

Final version resubmitted on 29 October 2001

Approved on 14 November 2001 